\section{Case Report}

Korean J Transplant 2021;35:112-115 https://doi.org/10.4285/kjt.21.0003
Received February 25, 2021

Revised April 8, 2021

Accepted May 14, 2021

Corresponding author: Taehee Kim Department of Internal Medicine, Inje University College of Medicine, 75 Bokjiro, Busanjin-gu, Busan 47392, Korea Tel: +82-51-890-6073

Fax: +82-51-890-6341

E-mail: thkim@paik.ac.kr

(c) The Korean Society for Transplantation This is an Open Access article distributed under the terms of the Creative Commons Attribution Non-Commercial License (http://creativecommons.org/licenses/ by-nc/4.0/) which permits unrestricted non-commercial use, distribution, and reproduction in any medium, provided the original work is properly cited.

\section{$\mathrm{KJT}^{\mathrm{K}}$ \\ KOREAN JOURNAL OF TRANSPLANTATION}

\title{
Outcomes of reused transplanted kidneys using cases from the Korean Network for Organ Sharing database
}

\author{
Eun Jin Woo ${ }^{1}$, Minhwa Kim ${ }^{1}$, Youn Jung Choi ${ }^{1}$, Jeongrim Lee ${ }^{1}$, Won Hyun Cho', \\ Chan II Park ${ }^{2}$, Yunmi Kim², Yeong Hoon Kim², Taehee Kim² \\ ${ }^{1}$ Korea Organ Donation Agency, Seoul, Korea \\ ${ }^{2}$ Department of Internal Medicine, Inje University College of Medicine, Busan, Korea
}

Due to organ shortages, the reuse of transplanted organs may be a good option for potential organ recipients. However, reports on the reuse of transplanted organs are rare. We retrospectively investigated cases of kidney donation since 2000 using the Korean Network for Organ Sharing database. Three cases of retransplanted kidneys were identified between 2000 and 2019. Of these three cases of kidney reuse, two involved reuse after a living-donor kidney transplant, and one case involved reuse after a deceased-donor kidney transplant. Another patient required a graftectomy due to bacterial infection immediately after transplantation. In two cases, the transplants were successful, and the kidneys have been functioning well for over 7 years. We believe that this case report highlights the opportunities for organ reuse among potential organ recipients and alleviates concerns about reused transplanted kidneys.

Keywords: Organ reuse; Kidney; Transplant; Adult; Follow-up studies

\section{INTRODUCTION}

After the inception of the Korean Network for Organ Sharing (KONOS) in 2000, the first reported case of reusing a donated or transplanted organ in Korea was a liver transplant in October 2008. The organ was redonated because the original recipient was braindead [1,2]. In 2011, Article 17, Reporting on Suspected Brain-Dead Patients and Requesting on Determinations of Brain Death and Article 20, Organ Procurement Organizations of the "Internal Organs Transplant Act" were amended to promote the use of organs from deceased organ donors in Korea [3]. Subsequently, the number of deceased donors greatly increased; nevertheless, the number of potential organ recipients on waiting lists increased.
In December 2019, there were 32,560 potential organ recipients on the waiting list. Of these, only 1,612 patients received an organ donation from 450 deceased donors. This indicates a significant shortage in organ donations from deceased donors related to potential organ recipients [4]. Reusing a transplanted organ from the original recipient could expand the availability of these organs. Here, we report on cases of reusing transplanted kidneys in Korea.

We requested data from KONOS regarding cases in which recipients received a solid organ between January 2000 and December 2019. Three cases involving the reuse of transplanted kidneys were retrospectively investigated. Data regarding the first donor, first recipient, and second recipient were obtained from each hospital. The following data were recorded: sex, age, medical history, cause of 


\section{HIGHLIGHTS}

- We investigated organ donation cases from the Korean Network for Organ Sharing database.

- Three cases of retransplanted kidneys were identified between 2000 and 2019.

- Our case report indicates the successful reuse of transplanted kidneys.

brain death, blood type, and test results at the time of donation.

All data were collected after obtaining the necessary approval from the Institutional Review Board of each hospital (IRB No. PNUYH 05-2020-045, BPH 20-0051, UUH 2020-03-018). Since this study was based on the database, the requirement for written consent was waived.

\section{CASE REPORT}

\section{Case 1}

The first recipient was a 44-year-old man with hypertension (HTN) and chronic kidney disease (CKD) who received a kidney transplant from his older sister in June 2005 and was taking cyclosporine, steroids, and mycophenolate mofetil (MMF). Seven years after the transplant, he experienced brain death due to spontaneous intracerebral hemorrhage (S-ICH), and his family agreed to organ donation. Human leukocyte antigen (HLA) typing results showed that the HLA-A, HLA-B, and HLA-DR groups were not mismatched (first donor and first recipient). Before the onset of $\mathrm{S}-\mathrm{ICH}$, the serum creatinine $(\mathrm{SCr})$ level was $1.2 \mathrm{mg} / \mathrm{dL}$. At the onset of S-ICH, the SCr level was $1.4 \mathrm{mg} / \mathrm{dL}$ and $1.3 \mathrm{mg} / \mathrm{dL}$ immediately before organ harvesting. Kidney ultrasound results showed that the kidney was $11 \mathrm{~cm}$ in size, with no morphological abnormalities.

The second recipient was a 53-year-old man with HTN, glomerulosclerosis, and CKD who had been on hemodialysis for 11 years. There were two HLA mismatches between the first and second recipients. Complement-dependent cytotoxicity crossmatch and flow cytometry (FCM) crossmatch results were negative between the first donor and second recipient and between the first and second recipients. Due to 7 years elapsing since the first recipient received a kidney transplant, there were difficulties in de- taching the adhesions around the kidney. Tacrolimus, steroids, and MMF were used as immunosuppressants. The $\mathrm{SCr}$ levels at 30 days, 1 year, and 2 years after the transplant were $1.2,1.3$, and $1.1 \mathrm{mg} / \mathrm{dL}$, respectively. There was no posttransplant delayed graft function or rejection, and no cases of cytomegalovirus or BK virus infection have been reported. Eight years after the transplant, the SCr level was $0.9 \mathrm{mg} / \mathrm{dL}$, and the patient was monitored in regular outpatient appointments.

\section{Case 2}

The first recipient was a 27-year-old woman with pediatric diabetes mellitus (DM), HTN, and CKD. She received a kidney transplant from her younger sister and a pancreas transplant from a deceased donor. A day after the transplant surgery, sudden cardiac arrest occurred, and cardiopulmonary resuscitation was performed for 45 minutes. Unfortunately, she experienced brain death due to hypoxic brain damage. The transplanted kidney was redonated to a second recipient 15 days after transplant surgery. The first recipient's SCr level was $0.7 \mathrm{mg} / \mathrm{dL}$ immediately after the kidney transplant and $0.8 \mathrm{mg} / \mathrm{dL}$ immediately before organ harvesting. Tacrolimus, steroids, and MMF were used as immunosuppressants during transplantation.

The second recipient was a 60-year-old man with HTN, $\mathrm{DM}$, chronic glomerulonephritis, and CKD who had been on hemodialysis for 4 years. There were four HLA mismatches between the first and second recipients. The complement-dependent cytotoxicity and FCM crossmatches with the first donor were negative. Crossmatching was not performed between the first and second recipients. Tacrolimus, steroids, and MMF were used as immunosuppressants. Three days after transplant surgery, Enterococcus faecium was found to grow in a blood culture from the first recipient. Therefore, the second recipient was treated with antibiotics.

While awaiting discharge, the patient experienced a sudden drop in hemoglobin levels. Mycotic aneurysm rupture of the renal artery anastomosis anterior wall was suspected on computed tomography scan, and a graftectomy was performed due to the risk of renal artery repair surgery.

\section{Case 3}

The first recipient was a 57-year-old woman with HTN and CKD who received her first kidney transplant 15 years prior. She had lost graft function after 11 years and subsequently underwent peritoneal dialysis. Two years later, she received a second kidney transplant from a deceased donor. The patient was taking tacrolimus, steroids, and MMF. 


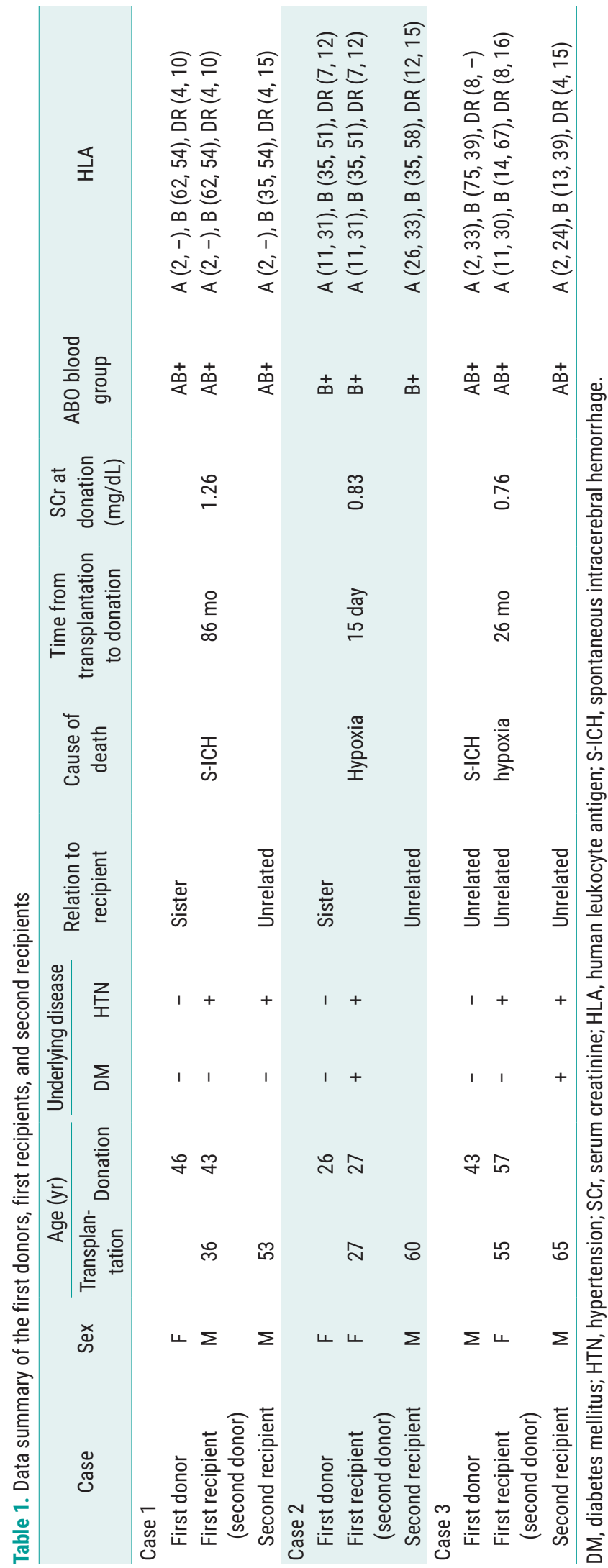

Two years later, she suffered a near-drowning accident, and cardiopulmonary resuscitation was performed for 11 minutes. She experience brain death due to hypoxic brain damage. The $\mathrm{SCr}$ level was $0.8 \mathrm{mg} / \mathrm{dL}$ immediately before the accident, $1.9 \mathrm{mg} / \mathrm{dL}$ at the time of the accident, and $3.5 \mathrm{mg} / \mathrm{dL} 1 \mathrm{~d}$ after the accident. The SCr level at the time of kidney donation was $1.9 \mathrm{mg} / \mathrm{dL}$, and the hourly urinary output was $170-280 \mathrm{~mL}$.

The second recipient was a 65-year-old man with DM, HTN, and CKD who had been on hemodialysis for 2 years. The panel reactive antibody test for the second recipient was $0 \%$. The blood samples from the first donor were not stored. The absence of donor-specific antibodies against the HLA of the first donor was determined using Luminex virtual crossmatching in a single antigen test [5]. The FCM crossmatch between the first and second recipients was negative. Tacrolimus, MMF, and steroids were used as immunosuppressants. The $\mathrm{SCr}$ levels at 30 days, 1 year, and 2 years after the transplant were $1.1 \mathrm{mg} / \mathrm{dL}, 1.1 \mathrm{mg} / \mathrm{dL}$, and $1.2 \mathrm{mg} / \mathrm{dL}$, respectively. There was no posttransplant delayed graft function or rejection; however, cytomegalovirus infection was identified and treated with valacyclovir. Seven years after the transplant, the SCr level was $1.3 \mathrm{mg} / \mathrm{dL}$, and the patient was monitored through regular outpatient appointments. Table 1 summarizes the data mentioned in the three cases.

\section{DISCUSSION}

Between October 2000 and December 2019, there were 24 cases in which organ donation from an organ recipient died was considered. In 15 of these cases, the organs were not reused because they were determined to be medically unusable because of their poor condition, hospital-related reasons, or the final recipient's refusal to undergo transplantation due to a marginal donor.

To date, there have been three cases of kidney reuse in Korea among transplanted organs from living or deceased donors. Among them, two patients are still living with well-maintained graft function, and graftectomy was performed in one patient due to posttransplant infection. There is a significant organ shortage in Korea. Living-donor transplantation must consider the risks and benefits to both the donor and recipient. Deceased donor transplantations are on the rise, but they cannot match the increasing number of potential organ recipients on the waiting list. 
To overcome the organ shortage, efforts have been made to promote the use of marginal donors and donations after cardiac death. One such effort is the reuse of transplanted organs; nevertheless, this raises several issues that need to be considered. First, a change in the perception of the transplant staff, including transplant surgeons, transplant physicians, and transplant coordinators, is required. The reuse of transplanted organs is not strongly supported by transplant staff. It causes additional problems regarding the patient's survival, including general postoperative complications that can occur after transplantation, organ survival rate, and immunological problems. Problems can also occur when harvesting the transplanted organ after reuse and cross-matching it in the absence of a blood sample from the first donor. To date, there have been only three cases of reuse of transplanted organs: one patient had an immediate postoperative infection, whereas the other two patients maintained good renal function for 7-8 years. As such, this study highlights the need to reevaluate the reuse of transplanted organs. Second, relatives face an ethical dilemma when deciding to donate organs [6]. However, they already have a good grasp of the concept of organ donation and may better understand the benefits of helping another human under these circumstances. This unique situation may present an ethical challenge to the family members of the first recipient; therefore, thorough discussion is needed [6].

As there were only three instances of kidney reuse, the survival rate of patients and grafts with a transplanted kidney cannot be directly compared to the numerous cases of primary kidney transplants. However, based on the findings in these cases, we believe that the graft function of the second recipient could be well-maintained, assuming proper crossmatching, suitable second recipients, predonation evaluation, and posttransplant management of early complications. We believe that this case report highlights the ample opportunities for organ reuse among potential organ recipients and alleviates concerns about reused transplanted kidneys.

\section{ACKNOWLEDGMENTS}

\section{Conflict of Interest}

No potential conflict of interest relevant to this article was reported.

\section{ORCID}

Eun Jin Woo Minhwa Kim Youn Jung Choi Jeongrim Lee Won Hyun Cho Chan II Park Yunmi Kim Yeong Hoon Kim Taehee Kim https://orcid.org/0000-0003-3206-7392 https://orcid.org/0000-0003-1879-1499 https://orcid.org/0000-0003-4542-8169 https://orcid.org/0000-0001-6038-5115 https://orcid.org/0000-0001-5916-6601 https://orcid.org/0000-0003-0896-0391 https://orcid.org/0000-0001-9281-9926 https://orcid.org/0000-0002-4101-9993 https://orcid.org/0000-0002-3001-234X

\section{Author Contributions}

Conceptualization: EJW, TK. Data curation: MK, YJC. Investigation: MK, YJC, CIP. Writing-original draft: EJW, TK. Writing-review \& editing: JL, WHC, YK, YHK, TK.

\section{Additional Contributions}

We thank Pusan National University Yangsan Hospital, Busan Paik Hospital, Ulsan University Hospital, and Korean Network for Organ Sharing (KONOS) for providing the data for this study.

\section{REFERENCES}

1. López-Navidad A, Caballero F. Extended criteria for organ acceptance: strategies for achieving organ safety and for increasing organ pool. Clin Transplant 2003;17:308-24.

2. Pasic M, Gallino A, Carrel T, Maggiorini M, Laske A, von Segesser $L$, et al. Brief report: reuse of a transplanted heart. N Engl J Med 1993;328:319-20.

3. Korea Legislation Research Institute. Internal organs, etc. Transplant act [Internet]. Sejong: Korea Legislation Research Institute; 2010 [cited 2021 May 30]. Available from: https://elaw.klri.re.kr/eng_mobile/viewer.do?hse$q=29060$ \&type=part\&key=36.

4. Korean Network for Organ Sharing (KONOS). KONOS waiting list [Internet]. Seoul: National Organ and Tissue Blood Management Service; 2014 [cited 2020]. Available from: https://www.konos.go.kr/konosis/index.jsp.

5. Park SJ, Oh SH, Kang MS, Kim TH, Kang SW, Yoon YC, et al. Reuse of a previously transplanted kidney from a deceased donor using Luminex virtual crossmatching: a case report. Transplant Proc 2014;46:2083-5.

6. Nemec P, Bedanova H, Ostrizek T. Successful re-use of the transplanted heart. Ann Thorac Surg 2010;90:13378. 